\title{
THE DYNAMIC STABILITY OF A ROTOR PASSIVE MAGNETIC BEARING WITH AN HALBACH-ARRAY
}

\begin{abstract}
SUMMARY
This paper describes the finite element method investigation of the permanent magnetic bearing (PMB) and spin tests of the PMB rotor suspension system. In order to increase the radial stiffness of the PMB, the Halbach-array configuration of the permanent magnets was used. The magnetic flux density of the PMB was investigated due to airgap. The test rig with the passive magnetic suspension is provided by one radial PMB on one end of the rotor. The rotor spin tests are performed for different desired unbalance, and rotor vibrations were presented.
\end{abstract}

Keywords: passive magnetic bearing, Halbach-array, magnetic suspension

\section{PASYWNE ŁOŻYSKO MAGNETYCZNE O KONFIGURACJI TABLIC HALBACHA JAKO DYNAMICZNY UKEAD STABILIZACJI WIRNIKA}

$W$ pracy przedstawiono analizę parametrów pasywnego tożyska magnetycznego, wykonana za pomocq metody elementów skończonych oraz zaprezentowano wyniki badań eksperymentalnych pasywnego zawieszenia magnetycznego wirnika $w$ ruchu obrotowym. $W$ celu zwiększenia sztywności promieniowej tożyska zbudowanego z magnesów trwatych zastosowano tablice Halbacha. Zaprezentowano rozkład strumienia magnetycznego dla różnych szerokości szczeliny powietrznej tożyska. Wykonano testy dynamiki pasywnego zawieszenia magnetycznego.

Stowa kluczowe: pasywne tożysko magnetyczne, tablice Halbacha, zawieszenie magnetyczne

\section{INTRODUCTION}

Nowadays, permanent magnet types of magnetic bearings are applied in many applications e.g. non-contact suspensions or bearingless drive systems. The passive magnetic bearings despite their instability (Earnshaw 1842); not restrict their technical use, especially in a clean environment and bio-compliance appliances. The most important advantage of passive magnetic bearings is "zero power" control (Fremerey 1988, Yakushi et al. 2000). The solid magnet type of application has a small size, null friction, and lightweight, high power-factor, high reliability, and efficiency. In opposite to active magnetic bearings, the permanent-magnets built bearings have no ability to stiffness control because of the static magnetic field. However, they overcome the active magnetic bearings by an unlimited bandwidth. In the active magnetic bearings, which have negative stiffness, energy is consumed to ensure the bias point. While this biasing tends to linearize the actuator, the bias current field itself does no work. Therefore, in many applications passive magnetic bearings provide the bias field, where external disturbances are controlled by magnetic forces generated by actively controlled electromagnets (Wilson and Struder 1981, Maslen et al. 1996). The primary advantage of this configuration is the elimination of power loss which is associated with the generation of the bias field. Other applications are compact-structure active magnetic bearings with solid magnets e.g. homopolar active magnetic bearings (Ehman et al. 2004). The other rotational machines consist of bearingless electric motors, e.g. permanent magnet syn- chronous bearingless motors (Satoh et al. 2000, Ohsawa et al. 2000, Redemann et al. 2000a, Redemann et al. 2000b).

In this paper the finite element method model of the passive magnetic bearing (PMB) and the spin tests of the rotor magnetic suspension system based on the PMB were performed. The test rig with the magnetic suspension provided by one radial permanent magnetic bearings on one end of the rotor is presented. The dynamic model of the radial permanent magnetic bearing is shown. Next, the discrete model of the PMB is investigated by using the finite element method (FEM). The finite element model was analysed by using COMSOL Multiphysics software. The magnetic flux loss and airgap flux density in the case of airgap change are presented for the Halbach configuration. Also, the nonlinear effect of the discrete 3D model of the PMB was analyzed.

This work mainly refers to the dynamic stability of passive magnetic suspension and rotor vibration control by the permanent magnetic bearing. The spin test of the rotor is conducted due to the transient stability of permanent magnets type of the rotor suspension. The rotor was successfully operated to speed of $4000 \mathrm{rpm}$. The load capacity of the passive magnetic bearing and the vibration damping is depicted due to the desired unbalanced mass of the rotor. Finally, the experimental tests, analytical calculations, and finite element results were compared and carried out.

\section{MODEL OF PERMANENT MAGNETIC BEARING}

The passive magnetic bearing is designed based on Halbach-arrays configuration. The Halbach-array is a special

\footnotetext{
* Faculty of Mechanical Engineering, Bialystok University of Technology, Bialystok, Poland; a.mystkowski@pb.edu.pl; leszek.ambroziak@gmail.com
} 
setup with the configuration of the permanent magnets, so there is a possibility to get the concentration of the magnetic flux in the specific, desired items, and remove it from less important or unwanted places (Halbach 1980). The examined passive magnetic bearing is composed of four pairs of the Neodymium-iron-boron $(\mathrm{NdFeB})$ magnets rings. These rings are axially magnetized, which means that magnetic poles are placed on the flat circle sides of the magnets. The scheme of the radial PMB based on the Halbach configuration is shown in Figure 1. The well-known relations of the passive magnetic flux density and the forces for solid magnets are given by:

$$
\begin{aligned}
& \bar{B}=(\bar{M}+\bar{H}) \mu_{0}, \quad \bar{B} \cdot \nabla=0 \\
& \bar{M}=\bar{M}_{r}+\chi \bar{H}
\end{aligned}
$$

where:

$$
\begin{aligned}
B & - \text { flux density, } \\
M & - \text { magnetization of the material, } \\
M_{r} & - \text { residual magnetization, } \\
\mu_{0} & - \text { vacuum permeability, } \\
\chi & - \text { susceptibility }\left(\chi=\mu_{r}-1\right), \\
\mu_{r} & - \text { permeability of the material. }
\end{aligned}
$$

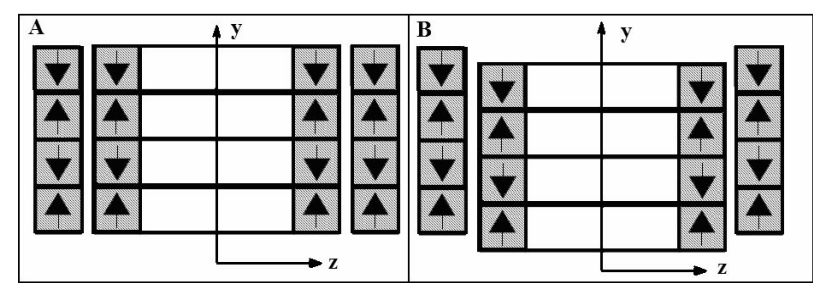

Fig. 1. PMB with a Halbach configuration

Force $F$ interacting between two permanent discs of magnets can be calculated by numerical methods for following relation (Bassani 2001, 2007):

$$
d \bar{F}=\bar{B} \times j d \bar{s}
$$

where the surface equivalent currents $j$ cross the material along elementary circuits $s$.

The magnetic dimensionless force $F^{\prime}$ between two discs of the magnets in the $z$ direction (see Fig. 1) is expressed as a function of $B$ under condition (Bassani 2007):

$$
\frac{\mu_{0}}{4 \pi} j_{1} j_{2} \Rightarrow \frac{\mu_{0}}{4 \pi} M_{r 1} M_{r 2} \Rightarrow \frac{1}{4 \pi \mu_{0}} B_{r 1} B_{r 2}
$$

and equals (Bassani 2006):

$$
F_{z}^{\prime}=\frac{F_{z}}{\frac{B_{r 1} B_{r 2}\left(R_{e}^{(1)}\right)^{2}}{4 \pi \mu_{0}}}
$$

where $R_{e}^{(1)}=g / g^{\prime}$ and $R_{e}^{(1)}=e / e^{\prime}$ for airgap $g^{\prime}$ and eccentricity $e^{\prime}$.
The FEM investigation of the discrete model of the PMB is concentrated on the magnetic flux distribution in the case of the geometry and the size change of the airgap. The airgap flux density was investigated in the case of an airgap change. The airgap flux density is described by following equation:

$$
B_{\text {gap }}=\frac{l_{m n} S}{\left(l_{m n}+l_{g n}\right) S^{\prime}} B_{r}
$$

where:

$$
\begin{aligned}
& l_{m n}-\text { normalized permanent magnet thickness, } \\
& l_{g n}-\text { lines of constant airgap length, } \\
& B_{r}-\text { remanent flux density, } \\
& S-\text { permanent magnet area, } \\
& S^{\prime}-\text { segment area. }
\end{aligned}
$$

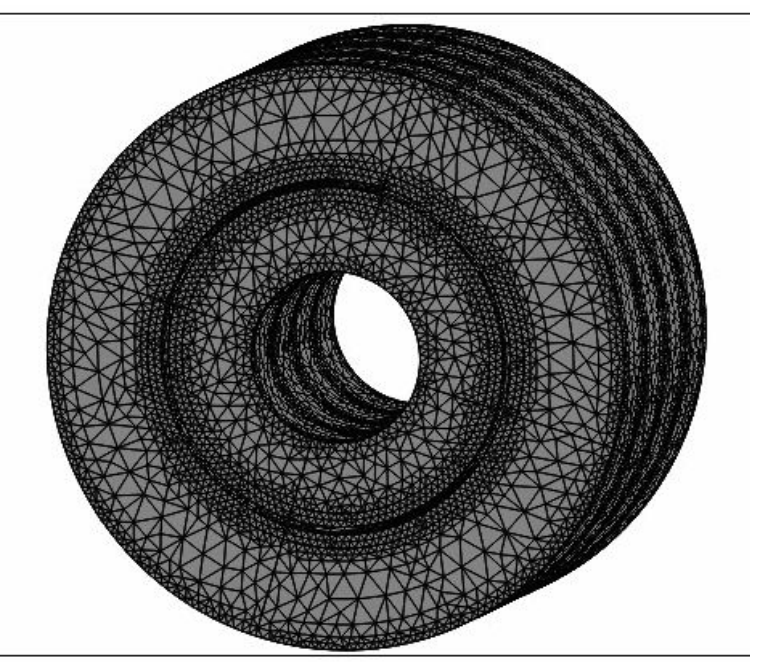

Fig. 2. 3D mesh model of PMB

In order to calculate the flux density and to predict the radial stiffness, the passive magnetic bearing 3D mesh model was built in COMSOL (COMSOL 2010). It consists of over 1 million nodes. The finite element model was made for permanent magnet rings and is shown in Figure 2. There are two mesh models for airgap and magnetic material, respectively. Mesh density increased in the airgap between the outer and inner discs. The flux density distribution over the airgap of the PMB was calculated by FEM of COMSOL and is presented in Figure $3 \mathrm{a}$ and Figure $3 \mathrm{~b}$. The airgap is equal to $1 \mathrm{~mm}$ (Fig. 3a) and $2 \mathrm{~mm}$ (Fig. 3b), respectively. In Figure $3 \mathrm{a}$, the maximum magnetic flux density located in the airgap is equal to $1.2 \mathrm{~T}$. For the airgap increase, magnetic field loss is significant, and radial stiffness goes down (see Fig. 3b). However, the airgap can not be too small because of possible mechanical contact e.g., at high rotor unbalance. Therefore, the airgap of $1 \mathrm{~mm}$ is a nominal value. The radial stiffness curve found by FEM calculations fits the experimental one (Mystkowski and Ambroziak 2010). The slope of the stiffness curve is $1.28 \cdot 10^{5} \mathrm{~N} / \mathrm{m}$. Finally, for the magnetic and geometric parameters calculated 
above and in the work (Mystkowski and Ambroziak 2010), the prototype radial passive magnetic bearing was built and presented in Figure 4.
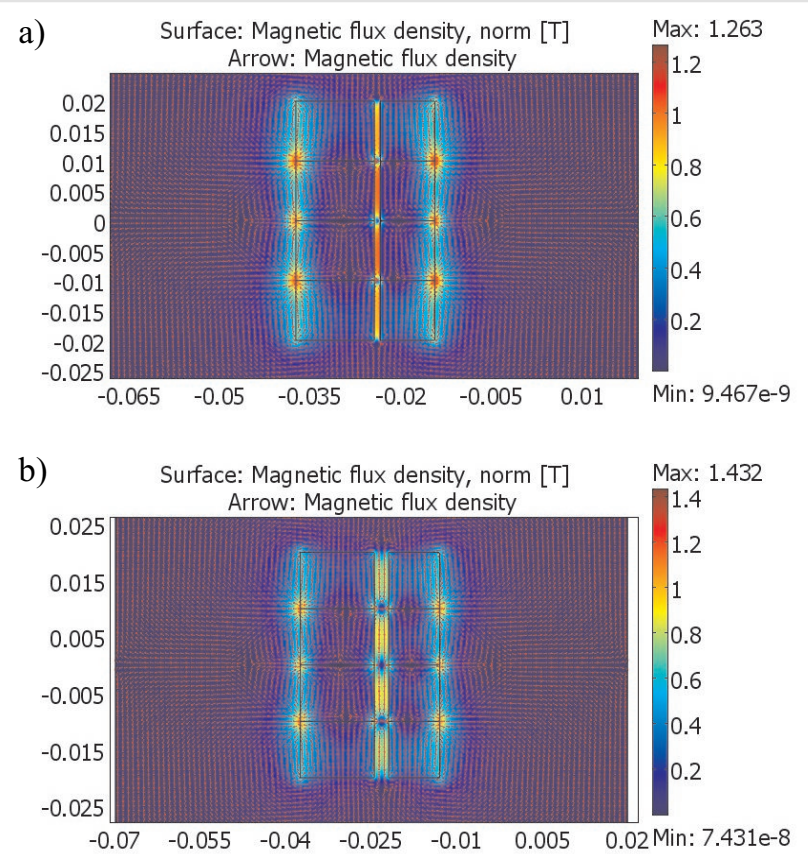

Fig. 3. Flux density due to airgap width: a) $1 \mathrm{~mm}$; b) $2 \mathrm{~mm}$

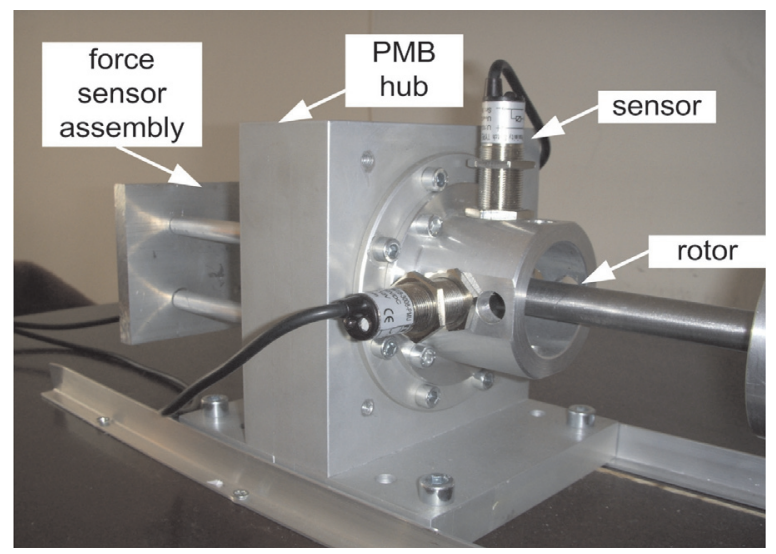

Fig. 4. The PMB in the test rig

\section{SPIN TESTS RESULTS}

The experimental studies allowed for the verifying of the finite element model of the PMB in the aspect of magnetic radial force generation and the ability to rotor vibration control. The spin tests are performed by using test rig, which was designed, built, and described in the work (Ambroziak 2010). The lab stand is shown in Figure 5. The rotor of mass $1.07 \mathrm{~kg}$ and total length $0.4 \mathrm{~m}$ is supported by the self-aligning ball bearing and passive magnetic bearing with the Halbach configuration. The rotor is driven by an electrical motor with an inverter. In order to measure the magnetic radial force in one direction, the tensometer force sensor was assembled. The radial displacement of the rotor was measured in two directions $x-y$ by using two inductive sensors. For more information about the test rig and the measurements please refer to (Ambroziak 2010).

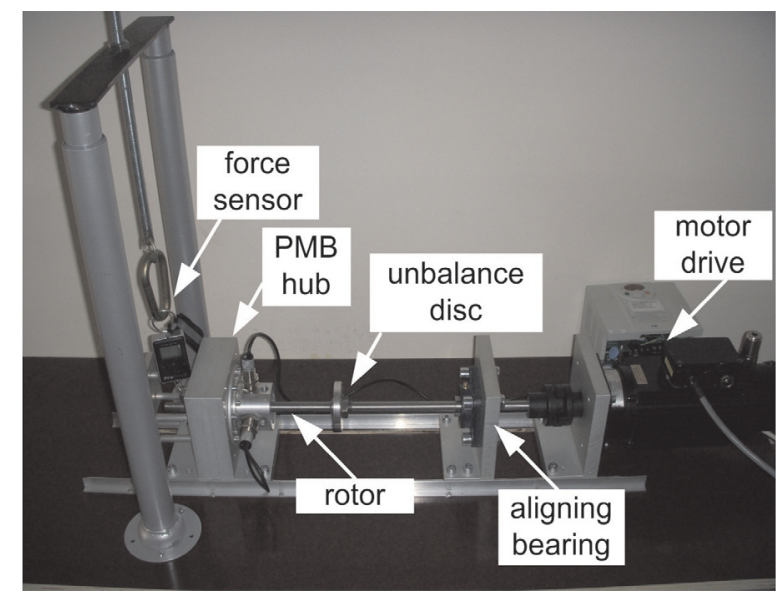

Fig. 5. Test rig

Spin testing consists of linearly increasing the rotor speed, where speed is increased to $4000 \mathrm{rpm}$. The rotor speed was limited at this point because of the rotor unbalance and for safety (there was not any shielding around the rotorbearing system). The rotor vibrations level was recorded. The passive magnetic bearing smoothly compensated the rotor vibrations and following resonances over the entire speed range. The orbit plot of the geometrical centre of the rotor for the sample rotational speed of $1160 \mathrm{rpm}$ is shown in Figure 6. The rotor speed of $1160 \mathrm{rpm}$ is near to the initial rotor resonance.

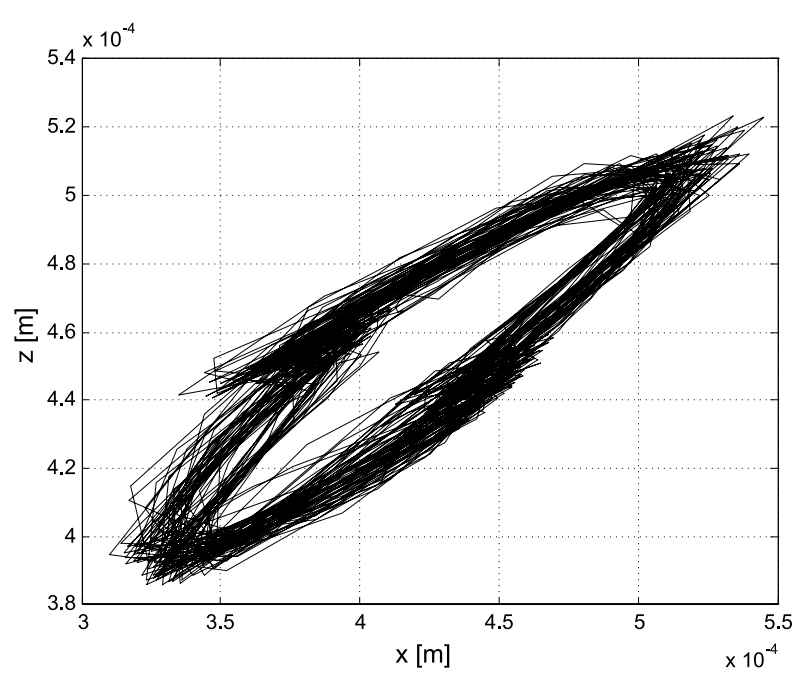

Fig. 6. Orbit plot at $1160 \mathrm{rpm}$

In order to evaluate the maximum bearing ability to disturbance compensation and load capacity, rotor unbalance was increased. Other spin tests were conducted with the added unbalanced mass via an unbalanced disk mounted on the rotor. The initial unbalanced mass was $35 \mathrm{~g}$ and the distance to the geometrical centre of the rotor was $30 \mathrm{~mm}$, 
next the unbalanced mass value was increased to $70 \mathrm{~g}$. The corresponding orbit plot is presented in Figure 7. The maximal amplitude (peak rotor unbalance equals $15 \%$ of rotor mass, but the rotor vibrations -to-peak) does not exceed $0.14 \mathrm{~mm}$, which means $7 \%$ of the airgap. When the rotor speed was increased to $4000 \mathrm{rpm}$, peak-to-peak amplitude equalled to $0.16 \mathrm{~mm}$ (Ambroziak 2010).

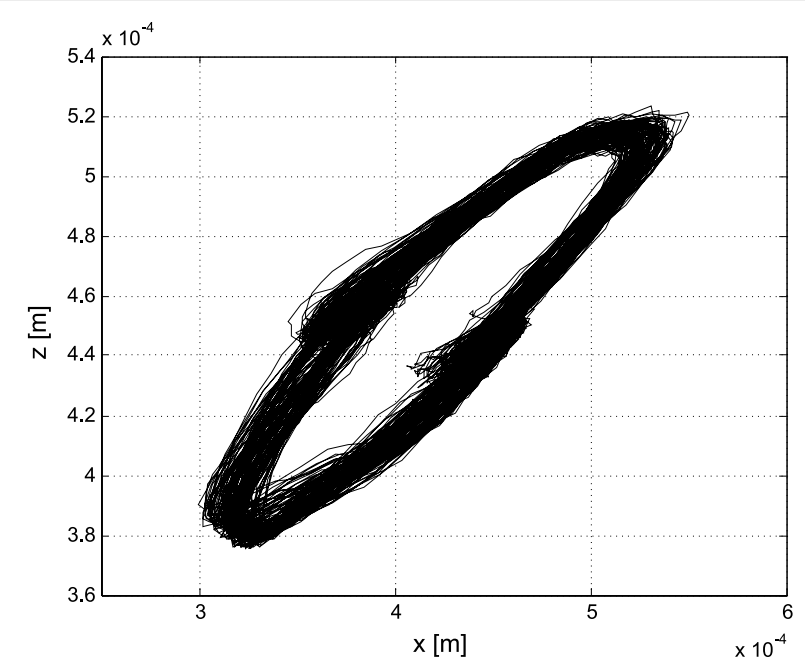

Fig. 7. Orbit plot at $1160 \mathrm{rpm}$ with extra unbalanced mass of $70 \mathrm{~g}$

\section{DISCUSSION}

Based on the design and calculations, permanent magnet types of magnetic bearings were built and tested due to vibration control at a prepared rotor suspension lab rig. The spin tests were conducted to $4000 \mathrm{rpm}$, and the rotor vibrates in a stable mode. Passive bearing load capacity depends on the arrangement/configuration, the energy density of the magnetic material and the geometry of the solid magnets. However, the implementation of the passive magnetic bearing requires a careful analysis of the magnetic field generated by permanent magnets, and assesses their material aspects. The introduction of the Halbach-arrays allows us to orient the magnetic field adequately, and to reduce the negative impact of the active component forces. Finally, the experimental results show the effectiveness of the passive bearing system in minimizing radial instability and rotor vibrations with limited unbalance force.

\section{References}

Ambroziak L. 2010, Project and application of passive magnetic bearing, Master thesis, Faculty of Mechanical Eng., Bialystok University of Technology (in Polish).

Bassani R. 2001, Permanent magnetic levitation and stability, Find. Trib. Micro-Macro, Kulver, pp. 547-554.

Bassani R., 2006, Earnshow S. (1805-1888) and Passive Magnetic Levitation, Meccanica 41, pp. 375-389.

Bassani R. 2007, Dynamic stability of passive magnetic bearings, Nonlinear Dyn, No 50, pp. 161-168.

COMSOL ver. 3.3 2006, AC/DC Module model library, User guide, COMSOL AB.

Earnshaw S. 1842, On the nature of molecular forces which regulate the constitution on luminiferrous ether trans, Cambridge Philos. Soc., 7, pp. 97-112.

Ehmann C., Sielaff T., Nordmann R. 2004, Comparison of active magnetic bearings with and without permanent magnet bias, Proc. of the Ninth International Symposium on Magnetic Bearings, Lexington, KY, USA, Aug.

Fremerey J.K. 1988, Radial shear force permanent magnet bearing system with zero-power axial control and passive radial damping, In Proc. 1st Internat. Symp. on Magnetic Bearings, ETH Zurich, Springer-Verlag, pp. 25-32.

Halbach K. 1980, Design of permanent multipole magnets with oriented rare earth cobalt material, Nucl. Instr. Meth., vol. 169, pp. 1-10.

Maslen E.H., Allaire P.E., Noh M., Sortore C.K. 1996, Magnetic bearing design for reduced power consumption, ASME Journal of Tribology, vol. 118 , No. 4 , pp. 839-846.

Mystkowski A., Ambroziak L. 2010, Investigation of passive magnetic bearing with Halbach-array, Acta Mechanica et Automatica, vol. 4, No 4.

Ohsawa M, Mori S., Satoh T. 2000, Study of the induction type bearingless motor, 7th Int. Symposium on Magnetic Bearings (ISMB), Zurich, pp. 389-394, August 2000.

Redemann C., Meuter P., Ramella A., Gempp T. 2000, Development and prototype of a $30 \mathrm{~kW}$ bearingless canned motor pump, IPEC, Japan, April, pp. 377-382.

Redemann C. et al. 2000, $30 \mathrm{~kW}$ bearingless canned motor pump on the test bed, 7th Int. Symposium on Magnetic Bearings (ISMB), Zurich, August, pp. 189-194.

Satoh T., Mori S., Ohsawa M. 2000, Study of induction-type bearingless canned motor pump, Institute of Electrical Engineering of Japan (IEEJ), International Power Electronics Conference (IPEC), Tokyo, Japan, April 3-7, pp. 389-394.

Wilson M., Studer P.A. 1981, Linear magnetic bearings, 5th Int. Workshop on Rare Earth-Cobalt Permanent Magnets and their Applications, Roanoke, Va, 7-10 June 1981.

Yakushi K., Koseki T., Sone S. 2000, Three degree-of-freedom zero power mag-netic levitation control by a 4-pole type electromagnet, In Proc. Internat. Power Electronics Conference IPEC, Tokyo. 